\title{
O aprendizado da docência - vozes em composição e disputa na constituição da experiência da profissionalidade
}

\section{Teaching learning - voices in composition and dispute constituting the professional experience}

\author{
Roseli Aparecida Cação Fontana* \\ Cláudio Borges da Silva**
}

\begin{abstract}
RESUMO
Neste texto, a partir das elaborações teóricas e conceituais de Bakhtin e de Thompson, com relação às noções de dialogia e de experiência, focalizamos a produção textual de um estudante no contexto da disciplina Prática de Ensino de História. Nela buscamos apreender e interpretar indicadores dos processos de apropriação e de elaboração dos conhecimentos científicoprofissionais relativos à docência e à escola na formação inicial do professor. O exercício analítico do material empírico escolhido deu visibilidade às vozes sociais dos interlocutores imediatos e não imediatos do estudante, e aos efeitos da mediação dessas vozes sobre suas elaborações, no desafio de conferir inteligibilidade às condições e contradições da experiência por ele vivida na escola.

Palavras-chave: experiência; dialogia; significação; formação de professores.
\end{abstract}

* Professora Doutora do Departamento de Ensino e Práticas Culturais da FE/UNICAMP e pesquisadora do Grupo AULA - Trabalho Docente na Formação Inicial - FE/UNICAMP.

** Doutor em Educação, Professor de História da Rede Municipal de Ensino de Campinas e pesquisador do Grupo AULA - Trabalho Docente na Formação Inicial - FE/UNICAMP. 


\begin{abstract}
This text, based in the theoretical and conceptual elaborations of Bakhtin and Thompson, related to the notions of dialogism and experience, focused the text production of a student inserted in the context of the History Teaching Practice discipline. We intended to assimilate and interpret the appropriation and elaboration process indexes of the scientific-professional knowledge related to teaching and the schooling of teachers' initial formation. The analytical exercise of the empiric material chosen has given visibility to the social voices of the immediate and non-immediate interlocutors of the student, and the mediation effects of these voices over their elaborations, upon the challenge of attesting intelligibility to the conditions and contradictions of students' experiences acquired at school.

Keywords: experience; dialogism; signification; teachers' formation.
\end{abstract}

\title{
Introdução
}

"É sempre mais fácil pensar sobre a escola ideal do que sobre a escola real; mais fácil descrever um programa escolar do que narrar como foi utilizado", assim Anne Marie Chartier (2007, p. 21) inicia um de seus textos sobre a compreensão da escola através da análise dos cadernos escolares, remetendo, seus leitores, às dificuldades que se enfrentam quando se deseja apreender o funcionamento cotidiano das práticas educativas.

Preocupações assemelhadas mobilizaram nossa inserção no projeto de pesquisa: "Produção do ensino, saberes cotidianos e científicos no imaginário de estudantes universitários" ". Com o objetivo de apreender e interpretar indicadores dos processos de apropriação e de elaboração dos conhecimentos científico-profissionais por estudantes de História, em seu contato com o cotidiano da escola básica, na disciplina Prática de Ensino, elegemos para análise os trabalhos finais por eles escritos nessa disciplina.

A opção pelo material escrito elaborado pelos estudantes fundamentouse no pressuposto de que os enunciados produzidos nas relações sociais de aprendizado indiciam a compreensão que os estudantes elaboram e o valor que atribuem às ações, aos gestos e às palavras com eles e por eles compartilhadas, tanto no âmbito das diferentes disciplinas e seus rituais no interior da universidade, quanto no âmbito de sua inserção na escola.

1. O referido projeto de pesquisa foi financiado pelo CNPq, no período de out. 2006 a out. 2008. 
Esse pressuposto é tributário das teses de Bakhtin (1986, 2003) acerca da centralidade da linguagem na constituição dos conhecimentos em circulação na vida social e da compreensão como dialogia, e se aproxima das teses de Thompson $(1979,1981)$ no tocante aos processos de formação humana como experiência, entendida como a interiorização e singularização das tradições culturais, nas condições históricas comuns da existência. Tanto a dialogia quanto a experiência definem um lugar a partir do qual, na análise da realidade social, determinação e agência humana podem ser apreendidas em seus nexos relacionais.

No texto ora apresentado, situamos, inicialmente, a pesquisa em seus pressupostos teórico-metodológicos. Em seguida, visando a uma aproximação dos sentidos da docência e da escola que foram compartilhados com os estudantes, descrevem-se de que maneira a disciplina Prática de Ensino foi proposta a uma turma do terceiro ano do curso de História de uma universidade de Campinas, ao longo do segundo semestre letivo do ano de 2008, e as especificidades do trabalho pedagógico desenvolvido na escola em que os alunos se inseriram. Finalmente, na terceira parte do texto são apresentados o relato de um estudante e as análises feitas a partir dele.

\section{Pressupostos teórico-metodológicos assumidos na pesquisa}

De acordo com Bakhtin a dialogia é o princípio explicativo da linguagem. A experiência discursiva individual se forma e se desenvolve em interação constante e contínua com os enunciados alheios e cada enunciado produzido é arena de encontro e de confronto entre opiniões de interlocutores imediatos ou de pontos de vista, visões de mundo, teorias, em circulação na comunicação cultural. Nesse sentido, cada enunciado concreto é um elo na cadeia da comunicação discursiva de um determinado campo e está voltado para seu objeto, para os sujeitos a quem se endereça e para os discursos sobre esse objeto, concordando com eles ou deles discordando. Por se constituir a partir de outros enunciados, respondendo ativamente a eles, cada enunciado concreto contém sempre mais de uma voz - a sua e aquela, ou aquelas, em relação às quais ele se constrói - mesmo que elas não se manifestem no fio do discurso produzido (FIORIN, 2006).

Focalizadas sob o ângulo da dialogia, as elaborações dos estudantes sobre a escola e a docência produzem-se em interlocução com suas formas de organização, com a legislação que as ordena, com os discursos que as configuram 
nos projetos pedagógicos, com as práticas proferidas e observadas nas relações vividas por eles na unidade escolar em que se inserem. Essas elaborações são também mediadas pelos conceitos e orientações colocados em circulação na disciplina Prática de Ensino, bem como pelas concepções de docência, de ensino, de educação escolar em disputa na formação histórica em que seu aprendizado está inscrito.

Essas referências e significados culturais constituem vozes sociais que expressam interesses e compreensões diversas, em consenso e em conflito, a que formadores e estudantes respondem em seus discursos, na condição de destinatários imediatos a quem se dirigem, ou na condição de visões de mundo, orientações teóricas, tendências filosóficas, polêmicas políticas, estéticas, pedagógicas, econômicas, que os constituem, e a seus interlocutores, como memória de sentidos (passada e futura), como história e cultura.

A interação viva dessas vozes sociais e as condições em que são elas produzidas participam dos enunciados dos estudantes e das escolhas dos formadores, indiciando-se nos usos da língua, na tonalidade expressiva de que se revestem, como também nas contradições, nas aproximações e consensos, no distanciamento, nas recusas e discordâncias, nos silenciamentos presentes na sua composição.

Do ponto de vista da dialogia, todo enunciado exibe seu direito e seu avesso, ou seja, as contradições constitutivas das diferentes vozes sociais que nele se manifestam. E, nesse sentido, longe de remeter à ideia de promoção do consenso, o conceito de diálogo, em Bakhtin, supõe a tensão entre vozes sociais em disputa, que modulam os sentidos da linguagem, configurando a compreensão como uma réplica ativa às palavras dos outros, que se produz no encontro/confronto entre essas palavras alheias e aquelas de que os sujeitos já se apropriaram e que os constituem. Como diálogo, a compreensão supõe, então, não apenas o reconhecimento dos significados e sentidos em jogo, mas uma tomada de posição frente a eles - de adesão ou de recusa, de acordo ou desacordo, de divergência ou de convergência, de conciliação ou de luta.

Dessa perspectiva, não há significados intrínsecos aos conceitos sistematizados que configuram o campo da formação docente, dos quais os estudantes apenas se apropriariam, nem um estudante genérico, nem relações de formação em abstrato. Os conceitos remetem às formações históricas em que se constituem e se sustentam, às coordenadas sociais, culturais e de subjetivação que atendem a necessidades práticas e a propósitos pragmáticos específicos. A eles, os formadores e os estudantes concretos - síntese de múltiplas relações sociais - respondem ativamente, elaborando-os a partir das posições sociais que ocupam, tanto na relação de ensino (sua condição imediata de produção), quanto nas relações sociais em que se inscrevem e se constituem (relações de 
parentesco, de trabalho, de gênero, de grupo geracional, etc.).

Nesse sentido, a linguagem, como princípio suposto de uma inteligibilidade comum, reconfigura-se como o lugar onde as dessemelhanças se revelam, uma vez que os significados não são apenas refletidos pelos sujeitos, mas também são refratados por eles, remetendo ao confronto de interesses sociais nos limites de uma só e mesma comunidade semiótica.

Em uma aproximação com Thompson, consideramos, neste trabalho, que tudo aquilo que os estudantes enunciam em seus textos é parte constitutiva da sua experiência de formação, inserção na escola e elaboração da professoralidade, visto que, conforme assinala Smolka (2006), não existe experiência sem significação. A experiência, como o conjunto das relações sociais vividas na cultura (THOMPSON, 1981), se produz e se singulariza como significação. Na sua raiz estão os signos, que constituem os diversos sistemas culturais que fazem parte da genética de todo o processo histórico, tais como os costumes, as regras visíveis e invisíveis de regulação social, hegemonia e deferência, formas simbólicas de dominação e de resistência, fé religiosa e impulsos milenaristas, maneiras, leis, instituições, ideologias. Signos, "que produzidos na relação com o outro, afetam os participantes das relações sociais, redimensionam e transformam a atividade humana, possibilitam a produção de sentidos" (SMOLKA, 2006, p. 108).

Longe de essencializar as subjetividades, a experiência indicia seus processos de constituição - sem escamotear as ambiguidades neles envolvidas - na participação dos indivíduos em diferentes grupos de pertencimento. Nela, o humano, concebido como ser inscrito na cultura e na história, atualiza e reinventa modos de ser, sentir e pensar, no entrecruzamento das condições de produção da vivência imediata com as determinações mais amplas da história social.

Experiência e significação, portanto, constroem-se dentro dos limites possíveis às relações sociais e, segundo Thompson, sua inteligibilidade só se torna possível no diálogo entre uma teoria provisória e explorativa e os dados empíricos - e não a partir de modelos que enquadram os fazeres humanos - na medida em que essa abordagem não dicotomiza os modos de produção dos sistemas de valores. Bakhtin, em uma direção similar, destaca que a compreensão dos enunciados produzidos não se restringe a uma análise de seu conteúdo, uma vez que eles significam na espessura e na instabilidade das relações sociais, implicando sua inscrição nas condições imediatas e mais amplas de sua produção, nas quais se explicitam as relações de poder entre interlocutores e discursos.

Neste estudo, com base nos conceitos de experiência e de dialogia, os relatos e os comentários feitos por escrito pelos estudantes foram considerados como fontes de indicadores dos sentidos da docência e da escolarização, postos em circulação e em elaboração pelos sujeitos envolvidos nesse processo. Para apreendê-los, privilegiamos uma análise enunciativa dos relatos, centrada no 
que foi dito e como foi dito pelos sujeitos, nas condições sociais de produção imediatas e mais amplas do próprio relato e da vivência relatada.

As condições imediatas dizem respeito às relações em que, situado como estudante ou estagiário, o autor do relato se dirige ao professor, que não apenas lhe ensina algo, mas estabelece condições a serem observadas no seu aprendizado da docência e avalia seu desempenho. As condições mais amplas dizem respeito às relações e organização do trabalho vividas na universidade e no interior da escola, à ideologia e aos valores hegemônicos e não hegemônicos, em circulação e confronto na formação social em que os sujeitos vivenciam seu aprendizado. No caso analisado, o aprendizado da docência está inscrito nas condições históricas da globalização e de suas implicações tecnicistas sobre os sentidos da profissionalidade docente e do papel social da escola. Tais sentidos, comprometidos com o mercado, têm sido divulgados com as propostas curriculares e metas educativas, definidas a partir dos projetos educacionais dos países economicamente dominantes, que têm sido impulsionadas por organismos internacionais e prescritas aos países emergentes, como condição do acesso a recursos econômicos e tecnológicos. Nessas condições, além do constrangimento em relação à autonomia dos diferentes países na definição de suas normas curriculares e de seus objetivos educacionais prioritários, a dimensão política das práticas educativas tem sido submetida ao gerenciamento, com base em critérios empresariais, dos resultados obtidos pelos sistemas educacionais em relação às metas globais, que passaram a configurar invariáveis antropológicas.

\section{A Prática de Ensino como uma das condições imediatas do proces- so de formação docente}

A disciplina Prática de Ensino de História, de cujo contexto foi retirado o relato escolhido para análise, fazia parte da grade do terceiro ano do curso e era o primeiro momento de atuação dos estudantes nas escolas, visto que as práticas que a precederam centravam-se na observação e descrição de aspectos específicos da dinâmica escolar.

Nessa disciplina, foi definido como objetivo principal a compreensão ativa dos modos de organização do trabalho pedagógico produzido no cotidiano de escolas de Ensino Fundamental, através da atuação compartilhada entre os estudantes e os professores que os receberam. Organizados em pequenos grupos, os estudantes se distribuíram por três escolas municipais de Campinas, indicadas pelo professor supervisor, em função de contatos previamente estabelecidos por ele com os professores de história dessas escolas. 
Em um primeiro momento da disciplina, os encontros entre o professor supervisor e alunos foram realizados na universidade e tiveram como foco a discussão de duas questões básicas: o papel da escola e do ensino de história, os perfis dos jovens e adolescentes e os desafios de organização do trabalho pedagógico com esse público. Nesse primeiro momento foram feitas também discussões pontuais acerca dos modos de inserção dos estudantes nas escolas, uma apresentação breve dos três professores com quem atuariam, o levantamento bibliográfico e algumas indicações de leitura sobre temáticas específicas que vinham sendo abordadas por esses professores em seu trabalho.

No relato que destacamos para análise, coube a Edson², seu autor, acompanhar um projeto de uso da informática no ensino de história. Assim, para ele e os demais alunos, que se inseriram na mesma escola, foram indicados, para leitura, dois artigos que abordavam - de perspectivas diferentes - a introdução das tecnologias de informação no processo de ensino. Em um deles a tecnologia era focalizada não como "ferramenta", mas como um processo comunicacional referente à relação entre diferentes sujeitos e destes com a máquina em contextos específicos, envolvendo a dimensão individual e coletiva da formação humana. A ênfase recaía sobre os novos processos cognitivos e as novas formas de aprendizagens que podem advir do uso das tecnologias de informação e comunicação, em grande medida, concebidos em oposição aos processos de construção de conhecimentos lineares, unidirecionais e desconectados do universo dos adolescentes promovidos pela escola (PORTO, 2006). Já o segundo artigo tratava do papel da informática na pesquisa em história, tanto aquela desenvolvida no âmbito acadêmico quanto na educação básica. Os autores historicizavam brevemente as influências dos usos dos computadores na investigação histórica e analisavam seus limites e potencialidades para o ensino. Ao contrário da perspectiva anterior concebiam a tecnologia como um instrumento de trabalho, um recurso de aprendizagem entre outros, com vantagens relacionadas à agilidade de acesso a informações e à diversidade de formas de processá-las, à riqueza multimídia e às possibilidades de compartilhamento de saberes (SILVA; FONSECA, 2007).

Em um segundo momento, os estudantes desenvolveram seus trabalhos nas escolas, acompanhando as aulas de história de uma turma do segundo segmento do ensino fundamental, em um dia da semana, durante quatro semanas. Todos foram orientados a registrar de modo cuidadoso cada ida a campo, descrevendo as relações de ensino-aprendizagem observadas e vivenciadas, procurando nelas

2. Cumpre destacar que embora tenha sido autorizada pelo estudante a utilização de sua produção como documentação no estudo em andamento, empregamos aqui um nome fictício para nos referirmos ao seu autor, bem como suprimimos o nome da escola onde atuou, de modo a garantir sua privacidade e a do professor que o recebeu. 
destacar aspectos para serem problematizados e analisados.

Ao final da disciplina cada aluno deveria entregar um relatório no qual, além dos registros mencionados, deveriam constar: uma caracterização do bairro, da escola e dos alunos, o plano de atuação desenvolvido com a turma e uma conclusão em que tratariam das aprendizagens tanto dos alunos com os quais trabalharam quanto das próprias aprendizagens, como docentes em formação.

No caso do relato escolhido para análise, do qual destacamos a conclusão, seu autor acompanhou um projeto de uso da informática no ensino de história, no qual uma das três aulas semanais da disciplina era destinada à construção de um "caderno eletrônico". Desenvolvido a partir de um tema de pesquisa definido entre professor e alunos, que tanto poderia estar diretamente ligado aos temas das aulas de história, quanto não, os alunos, reunidos em trios, utilizando como fontes de pesquisa sites da internet, eram orientados a produzir um texto que atendesse às demandas da pesquisa. Por fim, cada equipe tinha o compromisso de apresentar as conclusões de seus trabalhos para os demais colegas da turma. Nesse projeto, a atuação compartilhada dos estudantes implicou em tomar ciência das propostas de pesquisa em andamento na turma na qual estavam inseridos, acompanhar e subsidiar o desenvolvimento dessas propostas com os alunos.

O conjunto das condições descritas é constitutivo do texto que transcrevemos a seguir.

\section{A informática nas aulas de História -0 relato}

A utilização da informática na disciplina História pode parecer um pouco restrita para alguns professores, para alguns mais resistentes é impensável, como se a História, o acontecer humano estivesse completamente desligado da tecnologia. Crasso engano. A tecnologia é parte do acontecer humano que, por sua vez, é o tema de estudo da História.

O projeto da utilização da informática, auxiliando na pesquisa e no ensino de História na escola [em que atuei], vem dar boas colaborações para refletirmos sobre a utilização desta ferramenta para a pesquisa e para o ensino da História, rompendo barreiras e quebrando tabus que impunham resistência para esta união Informática (informatização)/História.

O projeto seguia a seguinte dinâmica: os alunos estudavam determinado tema na sala de aula e, posteriormente, iam para a sala de informática para transformar os temas paralelos que estavam ligados à temática central, vista em sala de aula, em projetos de apresentação, onde estes alunos, ao final do desenvolvimento deste projeto, apresentavam para todos os colegas em formato de seminário.

É fundamental explicar sucintamente como funcionou este projeto para podermos trabalhar as problemáticas detectadas dentro deste.

O primeiro ponto a ser trabalhado está completamente relacionado com a questão da dinâmica que nosso mundo contemporâneo apresenta, um 
alto grau de mudanças na sociedade, uma mobilidade muito grande, assim, os alunos que crescem neste contexto não mais aceitarão o modelo tradicional de ensino - lousa, giz, caderno e a sala de aula estagnada estes alunos querem fazer com que a construção do conhecimento se faça da mesma forma com a qual estão habituados no cotidiano, variando, tendo a possibilidade de avançar ou retroceder, de parar ou de continuar sem estar preso a procedimentos impostos por métodos ultrapassados de ensino. Quando em contato com o computador o aluno escreve e apaga o que escreveu com uma facilidade muito maior, de forma mais natural, este mesmo aluno busca, com o apoio da internet, diversas e diversas informações em questão de minutos e se determinada informação não supre sua necessidade, um simples comando para mudar de endereço soluciona seu problema. Desta maneira, temos pontos de vista diferentes entre os alunos e o professor quanto a esta questão do papel do projeto de informática na construção de um trabalho ou de uma pesquisa em história. $\mathrm{O}$ aluno recebe a mudança da forma de aprendizagem como uma entrada no mundo ao qual está acostumado - mundo virtual, utilizando o computador e suas ferramentas - e a saída daquele ambiente ultrapassado e estagnado da sala de aula, promovendo uma relativa identificação com o tema a ser pesquisado, mesmo que este não seja familiarizado com o assunto, a colaboração da informatização o leva mais próximo do assunto e fornece conteúdos e materiais mais "palpáveis" que rompem com a total abstração a que é submetido na sala de aula. Já para o professor o projeto do uso da informática tem como papel principal a fixação do conteúdo trabalhado em sala de aula, cumprindo assim, de forma eficaz, o currículo proposto pela escola e desenvolvendo um bom trabalho de ensino. Veja que as formas como os sujeitos observam são absolutamente diferentes quanto ao papel do projeto: enquanto o aluno vê o projeto como uma forma de escapar ao velho e tradicional método de ensino, tornando a aula mais interessante, o professor enxerga o projeto como uma complementação deste método tradicional utilizado na sala de aula.

Um segundo ponto de problematização é o distanciamento entre o aluno e o tema a ser pesquisado, ou mesmo, o aluno e as ferramentas do computador. Aqui também observamos uma dicotomia. Enquanto alguns alunos possuem uma maior facilidade para lidar com o computador e a informatização, outros, por não possuírem acesso constante a este tipo de equipamento, apresentam certa dificuldade e uma resistência quanto à sua utilização, por isso se faz necessário distribuir os alunos nos grupos de uma forma que todos possam ter ajuda um do outro para promover não somente o aprendizado do conteúdo pesquisado, mas também da utilização do computador. Já ligado à identidade com o tema, é aqui que entra o papel do professor de aproximar o tema pesquisado com a realidade vivida pelo aluno, ou mesmo construir a noção, neste aluno, de que ele é um sujeito histórico, da mesma forma como os personagens que estão sendo pesquisados por ele também o são.

Muitas vezes o que distancia o aluno do conhecimento é justamente esta falta de identidade, esta dificuldade em compreender que todos os seres humanos, independente da região onde moram, fazem ou fizeram 
parte de um processo histórico, do processo do acontecer humano, que gerou alterações em outras sociedades em outro tempo, ou na sua própria sociedade em seu próprio tempo.

Retornando para a discussão da nova dinâmica em que as nossas crianças estão sendo criadas, chamamos a atenção para uma outra problemática que se encontra na relação professor e aluno (ou seria melhor dizer mediador e construtor do conhecimento?) A forma como observamos o ensino se encontra ultrapassada se apontarmos o professor como um "professor detentor do conhecimento" e a escola como "instituição que fornece os meios de conhecimento" e o aluno como alguém que está ordenado a aprender sem contestar, sem participar da construção de seu próprio conhecimento.

O projeto da escola pode ser observado como expressão mais clara de que a forma de levar o aluno a construir o seu conhecimento, ou mais diretamente ensinar o aluno, se modificou. Se antes a escola e o professor eram os detentores do conhecimento, hoje, século XXI, diante desse processo acelerado em que o mundo contemporâneo se encontra o professor passou a ser um mediador do conhecimento, a escola um local de confluência de todo o conhecimento adquirido pelo aluno e organizador deste conhecimento em um padrão lógico, e o aluno é o seu próprio professor, porque é ele próprio que deve realizar seu ensino (ou seria sua aprendizagem?), e o professor desempenharia o papel de coordenar e auxiliar este aluno a moldar seu conhecimento adquirido.

O conhecimento está em toda parte, o avanço dos meios de comunicação popularizam as formas e os conteúdos de pesquisas, assim existe um motivo a temer do professor e da escola, resistindo. O que há para ser feito é justamente aceitar que o monopólio de detentores do conhecimento acabou, que hoje escola e professores são mediadores e organizadores do conhecimento que será construído pelo aluno.

Finalizando, se faz necessário também de acordo com a experiência que pudemos observar, não permitir que a construção do conhecimento ganhe características de disputa, porque não é esta a proposta, pelo contrário, a proposta é a troca de conhecimento ao final dos trabalhos e não tentar ser melhor que o outro grupo. Porém, é compreensível que os alunos se vejam nesta situação já que esta é a principal forma de pensar do século XXI, mas o papel do professor é destacar a construção do conhecimento onde todos os grupos respeitem e tirem dos outros importantes lições e aprendizados sem discriminar a diferença no pensar.

\section{A informática nas aulas de História - a análise}

Em resposta ao seu interlocutor imediato, o professor-supervisor, Edson estrutura suas elaborações conclusivas em duas partes. Na primeira delas, situa os termos em que se insere na discussão proposta. Assumindo o argumento de que a tecnologia é parte do acontecer humano e, como tal, intrínseca à história, 
Edson considera como equivocada sua recusa pelos professores (para os mais resistentes, é impensável), qualificando-a como incompreensão da própria história (como se a História, o acontecer humano estivesse completamente desligado da tecnologia).

O uso de expressões como crasso engano, mais resistentes, impensável, completamente desligado, confere ao enunciado sua tonalidade expressiva, sugerindo a obviedade da ideia defendida, a desqualificação daqueles que se opõem a ela, bem como a indicação do posicionamento pertinente frente à questão da incorporação das tecnologias da informação ao processo de ensino. Essas expressões indiciam também imagens e juízos generalizantes formulados por Edson em relação aos professores de história. Apesar de se inscrever nesse grupo social, como professor-substituto em escolas públicas estaduais ${ }^{3}$, Edson, em seus comentários, passa o largo das condições em que o exercício cotidiano da docência é vivido e nas quais são protagonizadas as disputas em torno da inserção das tecnologias da informação na educação escolar.

As problematizações solicitadas pelo professor compõem a segunda parte do texto em análise. Nelas, o primeiro ponto destacado por Edson é a participação das tecnologias da informação na constituição dos indivíduos nas sociedades contemporâneas (nosso mundo contemporâneo apresenta, um alto grau de mudanças na sociedade) e o contraste entre o modelo flexível e dinâmico de aprendizagem, que nelas reconhece, com o modelo tradicional de ensino escolar. Edson escreve:

os alunos que crescem neste contexto não mais aceitarão o modelo tradicional de ensino - lousa, giz, caderno e a sala de aula estagnada - estes alunos querem fazer com que a construção do conhecimento se faça da mesma forma com a qual estão habituados no cotidiano, variando, tendo a possibilidade de avançar ou retroceder, de parar ou de continuar sem estar preso a procedimentos impostos por métodos ultrapassados de ensino.

O modo como Edson constrói essa contraposição é tributário de uma voz social hegemônica que, desde a chegada da Internet em 1994, através do slogan "Clicar é saber" passou a divulgar a crença de que qualquer um pode apropriarse dos conhecimentos disponíveis na rede, com toda liberdade, sem se deslocar e sem esforço (CHARTIER, 2004).

Essa voz, de cunho tecnicista, apresenta as tecnologias da informação

3. Cumpre destacar que embora Edson estivesse cursando a disciplina Prática de Ensino do terceiro ano do curso de História ele já havia feito as demais disciplinas, faltando apenas as "pedagógicas" e, nesta condição, exercia o papel de professor-substituto em escolas públicas estaduais há dois anos, uma condição comum entre os alunos estagiários. 
como aptas a moldar de modo homogêneo o processo de formação humana e de transformar a escola, em face da identificação dos alunos com a diversidade das fontes de informação disponíveis na rede, em termos dos conteúdos tratados e das formas de tratamento a eles conferidas. Ela aparece no enunciado de Edson, quando ele assinala que:

em contato com o computador o aluno escreve e apaga o que escreveu com uma facilidade muito maior, de forma mais natural, este mesmo aluno busca, com o apoio da internet, diversas e diversas informações em questão de minutos e se determinada informação não supre sua necessidade, um simples comando para mudar de endereço soluciona seu problema.

No debate instaurado em torno dos impactos das novas tecnologias, no entanto, a essa voz hegemônica, contrapõem-se outras, como, por exemplo, a de Assmann (2005, p. 19) que, reconhecendo nas novas tecnologias "um papel ativo e co-estruturante das formas do aprender e do conhecer" e valorizando suas possibilidades de democratizarem o acesso ao conhecimento, critica "um certo tecnootimismo [...] com escassa previsão de interferência ativa dos sujeitos humanos, alentados por uma sensibilidade conscientemente cultivada" e alerta para o fato de que "o passo da informação ao conhecimento é um processo relacional humano, e não uma mera operação tecnológica" (ASSMANN, 2005, p. 28 e 15).

Santos (2003, p. 74), sem negar o aspecto democrático de circulação da informação que existe na internet e as conexões que ela possibilita, considera "ingênuo acharmos que a internet é um território livre". Lembrando que faz parte do próprio mito do progresso alardear que todas as tecnologias são democráticas, ele sinaliza que as novas tecnologias não estão ao alcance de todos e que, mesmo os incluídos não são iguais. Segundo ele, o problema não está só no acesso à informação, mas em "como se vai processá-la para fazer dela um instrumento de conhecimento" (SANTOS, 2003, p. 74-75).

Chartier (2004), na mesma perspectiva adotada por Santos, chama a atenção para as novas discriminações instauradas e mantidas por essa tecnologia, em função das contradições que sustentam sua produção e circulação. Essas discriminações se manifestam tanto nas relações sociais mais amplas, entre países e classes, quanto nas relações cotidianas, em que os efeitos da participação nessa esfera de atividade evidenciam-se na constituição da experiência imediata e identitária dos indivíduos. Nesse âmbito, Chartier apresenta resultados de pesquisas que têm identificado que, ao contrário do que fazem crer certos discursos acerca da facilidade com que as novas gerações se relacionam com a máquina, muitos 
alunos, em especial as mulheres, tanto no ensino médio quanto no superior, manifestam uma grande recusa pelas novas tecnologias e que as adotam, como uma necessidade, quando as instituições de ensino as promovem.

Partindo de perspectivas diferentes, tanto a abordagem de Assmann, centrada na dimensão cognitiva e relacional do processo de conhecimento, quanto a abordagem de Santos e de Chartier, que prioriza a compreensão das novas tecnologias no âmbito das multideterminações sociais em que são produzidas e postas em circulação, confluem na crítica ao viés tecnicista hegemônico que preside a divulgação das novas tecnologias da informação.

Esses pontos de vista, embora não sejam inicialmente considerados no discurso de Edson, ganham visibilidade em seu enunciado quando a experiência concreta vivida na escola é a ele incorporada. As evidências apreendidas no laboratório de informática desorganizam o tom genérico e homogeneizante, situado para além dos sujeitos concretos e dos antagonismos sociais, assumido inicialmente por Edson, dando visibilidade a possibilidades diferentes daquelas por ele anunciadas. Essas possibilidades são o foco de sua segunda problematização, apresentadas sob o título de distanciamento entre o aluno e o tema a ser pesquisado e distanciamento do aluno e as ferramentas do computador.

Nas relações de ensino-aprendizagem acompanhadas de perto, Edson apreende desigualdades existentes entre os alunos, no acesso ao computador e suas linguagens: enquanto alguns alunos possuem uma maior facilidade para lidar com o computador e a informatização, outros, por não possuírem acesso constante a este tipo de equipamento, apresentam certa dificuldade e uma resistência quanto à sua utilização. Embora as enuncie como diferenças de atitude dos alunos em relação ao computador - dificuldade e resistência ele as atribui a condições de acesso e de uso, que estão além de disposições estritamente individuais.

Por sua vez, o que Edson considera como distanciamento entre o aluno e o tema a ser pesquisado remete à insuficiência da tecnologia para garantir, por si mesma, o envolvimento dos alunos com o aprendizado, a pesquisa e com a elaboração do conhecimento. Os alunos não produziram sozinhos o trabalho proposto pelo professor e aquilo que produziram parecia distante do conhecimento histórico:

Muitas vezes o que distancia o aluno do conhecimento é justamente esta falta de identidade, esta dificuldade em compreender que todos os seres humanos, independente da região onde moram, fazem ou fizeram parte de um processo histórico, do processo do acontecer humano, que gerou alterações em outras sociedades em outro tempo, ou na sua própria 
sociedade em seu próprio tempo.

As considerações de Edson, ainda que breves e lacunares em termos da descrição daquilo que foi produzido pelos estudantes, aproximam-se, em alguma medida, da advertência de Santos em relação à desigualdade que permanece, a despeito do acesso, quando se considera os termos em que a informação possibilitada é processada.

Suas breves considerações também podem ser cotejadas com as evidências de pesquisa, reunidas por Chartier (2004), que mostram que os aprendizados informais e autônomos dos jovens, em sua relação com os computadores, são bastante seletivos. Muitos dos usuários novatos se contentam com programas de jogos e consultas de informação na tela, limitando-se a um uso restritivo e repetitivo da máquina, na ausência de uma tutoria individualizada e dos imperativos de um projeto intelectual bem construído.

Em relação aos hipertextos, Chartier destaca, em uma consideração, da qual aquela esboçada por Edson também se aproxima, que a riqueza de suas possibilidades, como um corpus gigantesco e único, disponível aos navegadores do ciberespaço, assenta-se no pressuposto de que "a memória (humana) do cibernauta encontra-se já educada e estruturada podendo então questionar e organizar o material selecionado a sua conveniência" (CHARTIER, 2004, p. 198). Isto se dá porque os vínculos que distinguem uma informação de um conhecimento não estão presentes na máquina e nem são assegurados por ela. Eles são constituídos na memória do leitor e integram cada dado e cada relação dentro de um conjunto que lhes outorga significado e valor de uso. Na ausência de uma memória de sentidos compartilhada em um projeto intelectual em comum, os vínculos refletem os interesses momentâneos de leitores individuais, configurando, nas palavras de Chartier (2004, p. 199), "um zapping generalizado", que muitas vezes resulta na descontextualização e empobrecimento do sentido daquilo que se leu.

Em relação à produção de textos, uma tarefa implicada na construção dos cadernos eletrônicos propostos pelo professor, Chartier assinala que a escritura hipertextual recorre mais frequentemente à colagem, à montagem de documentos $\mathrm{e}$ à justaposição de ilustrações, distanciando-se da escrita convencional, em termos da estruturação nem sempre linear e coesa dos textos produzidos pelos estudantes.

Assim, do ponto de vista da incorporação das tecnologias da informação ao ensino, Chartier assinala que uma nova leitura, uma nova escrita e novas formas de apropriação cultural estão em produção, em coexistência, e não ruptura, com aquelas que, sob a supremacia da cultura escrita, constituem os conhecimentos escolares. A leitura e a escrita hipertextual, “apesar das alegrias que podem pro- 
porcionar e das evocações que desencadeiam, ainda não conduzem à construção de conhecimentos no sentido habitual (ou escolar) do termo" e a familiaridade precoce com a máquina não assegura "que se eliminem os problemas cognitivos colocados pelas experiências de espaço e tempo nas interações "virtuais" (CHARTIER, 2004, p. 200 e 202).

Aquilo que Edson aprende nas relações de ensino "reais" e denomina como distanciamento entre o aluno, o tema e o computador, remete ao movimento das vozes sociais em disputa no próprio conceito de sociedade do conhecimento.

De acordo com uma análise de Sergio Rouanet (2002), o conceito de sociedade do conhecimento remete a um fato, a uma ideologia e a uma utopia. Como fato, a sociedade do conhecimento é indiscutível e pode ser confirmado empiricamente que o conhecimento científico-tecnológico passou a desempenhar um papel decisivo na economia e, por meio dela, na sociedade.

Como ideologia, considerada em seu sentido mais clássico, como conjunto de ideias destinadas a mistificar relações reais, a serviço de um sistema de dominação, o conceito de sociedade do conhecimento dissimula as relações sociais reais em que se assenta, ao redefinir a sociedade de conhecimento como sociedade de informação, tratando informação e conhecimento como se fossem sinônimos. Rouanet explica que o primado atribuído à informação é falso, mas tem uma base real. Ele é falso em relação aos grandes contingentes da população que, bombardeados por informações, que funcionam como sinais, são dispensados do trabalho reflexivo que transformaria os conteúdos do mundo exterior, devidamente processados pelo aparelho psíquico, em verdadeiros conhecimentos. Mas é real para a elite que opera com o conhecimento técnico-científico. Nesse âmbito a informação se transformou na grande força produtiva, tendo se tornado vital para assegurar o funcionamento da economia, para as decisões políticas e para a atuação dos próprios polos de geração do conhecimento. $\mathrm{Ou}$ seja, a aquisição e transmissão do conhecimento, hoje em dia, segundo Rouanet, são inconcebíveis sem as novas tecnologias de informação e comunicação, mas o que é "decisivo é o conhecimento técnico-científico injetado no sistema produtivo". Ele constitui a grande força dinâmica para a reprodução material da sociedade. Nesse sentido, Rouanet enfatiza que travestir a sociedade de conhecimento como sociedade de informação "significa bloquear os caminhos para uma ação questionadora eficaz, que não passa prioritariamente pela conexão com uma rede mundial de comunicação [...] mas pelo acesso amplo ao conhecimento" (ROUANET, 2002).

Lembrando que toda ideologia contém em seu avesso uma dimensão utópica, Rouanet (2002) destaca que a contradição entre informação e conhecimento explicita que a sociedade do conhecimento "é uma utopia concreta", na medida em que ela contém "um conjunto de representações fundadas numa esperança 
objetiva, instruída por tendências já presentes no real". Na ideologia da sociedade da informação, assinala ele, inscreve-se uma utopia moderna da sociedade do conhecimento, "inspirada pela fantasia iluminista da emancipação por meio de um conhecimento acessível a todos" (ROUANET, 2002). Essa utopia moderna não nega a importância da informação, mas a distingue do conhecimento e a vê como um meio para o conhecimento e pressupõe "a superação do hiato cognitivo e digital", que separa os países detentores das novas tecnologias dos demais membros da comunidade internacional, pelo acesso igualitário de todos ao estoque universal de conhecimento.

No enunciado de Edson, as vozes da sociedade do conhecimento, como fato, como ideologia mistificadora e como utopia, entrechocam-se no desafio de conferir inteligibilidade à experiência compartilhada na escola. Frente aos distanciamentos apreendidos, Edson invoca a atuação do professor no sentido de desenvolver ações pedagógicas intencionais de modo a garantir o acesso igualitário às tecnologias da informação e à exploração de seus usos. Nessa direção, mediado pela utopia, Edson elabora sua terceira problematização, focada no papel do professor e da escola.

Em estreita interlocução com os textos disponibilizados para estudo na disciplina, Edson reproduz em seu enunciado a maneira como a escola é redefinida em um deles (PORTO, 2006): um local de confluência de todo o conhecimento adquirido pelo aluno e organizador deste conhecimento em um padrão lógico.

Na discussão do papel do professor, além de instaurá-lo como mediador das relações entre os alunos e de sua organização para o aprendizado, ao apontar que se faz necessário distribuir os alunos nos grupos de uma forma que todos possam ter ajuda um do outro para promover não somente o aprendizado do conteúdo pesquisado, mas também da utilização do computador, Edson também o define como referência na elaboração de um projeto intelectual construído em comum - o papel do professor [é] de aproximar o tema pesquisado com a realidade vivida pelo aluno. Ele o compromete diretamente (e até diretivamente, ao sugerir que cabe ao professor construir a noção, neste aluno, de que ele é um sujeito histórico) com o desenvolvimento cognitivo dos alunos, no sentido de assegurar a apropriação de significados e sentidos de uma memória comum, que é condição do processo de significação, da capacidade de abstração e da identidade histórica.

Outra consideração relativa ao papel do professor, nascida da experiência, diz respeito à competição identificada entre os jovens alunos, assim enunciada por Edson: se faz necessário [...] não permitir que a construção do conhecimento ganhe características de disputa, porque não é esta a proposta, pelo contrário, a proposta é a troca de conhecimento ao final dos trabalhos e não tentar ser 
melhor que o outro grupo.

Edson aproxima-se dessa dimensão da experiência, justificando o comportamento dos alunos como compreensível, uma vez que a competitividade é a principal forma de pensar do século XXI. Ao fazê-lo, inscreve a escola no cenário histórico-cultural mais amplo, marcado pelos conflitos de interesses e valores e, nesse âmbito, reelabora o papel da escola e do professor, atribuindo-lhes um lugar de não-neutralidade nesses conflitos: o papel do professor é destacar a construção do conhecimento onde todos os grupos respeitem e tirem dos outros importantes lições e aprendizados sem discriminar a diferença no pensar.

As vozes que incorpora ao texto deslocam o viés tecnicista e a polarização entre a modernidade das novas tecnologias e o arcaísmo da escola e do professor, que marcam suas elaborações iniciais. Elas dão visibilidade aos embates entre os limites das condições sociais de produção da escola real e o desejo de transformá-la em uma instituição que contribua para assegurar o acesso igualitário aos conhecimentos produzidos pela humanidade.

Na utopia de outra escola, Edson mantém a centralidade da atividade do aluno na condução do processo pedagógico, por ele valorizada desde o início do texto. A aproximação, por vezes ambígua, entre a atividade direcionadora do professor e a centralidade da atividade do aluno no processo de aprendizado, indicia que a experiência tanto produziu o efeito de redimensionar concepções, quanto de reafirmar princípios assumidos pelo estudante, na sua relação com as vozes que foram sendo por ele incorporadas.

O exercício analítico, mediado pelas categorias da dialogia e da experiência, permitiu-nos compreender a presença, nos enunciados de Edson, de seus interlocutores imediatos e não imediatos, e os efeitos da mediação dessas vozes sociais sobre suas elaborações. Também explicitou um caminho na formação que passou pela relação dinâmica entre a sistematização das teorias pedagógicas, o processo de inserção do estudante em sala de aula, a documentação minuciosa das relações de ensino ali vividas e sua problematização, a voz do professor formador e aquelas por ele convocadas e os sentidos sociais-pessoais que constituíam o estudante singular. Nessas condições, a compreensão das relações entre a teoria e a prática demandou, para ser apreendida e elaborada, um pensamento "não-indiferente" às possibilidades e constrangimentos dos sentidos da docência.

4. Conforme Amorim (2007, p. 19): "Para tornar o pensamento não-indiferente, é preciso responder por ele levando em conta o contexto em que nos encontramos. E o contexto será sempre uma arena onde diferentes valores se afrontam, engendrados nas diferentes posições sociais que ocupamos. O pensamento tornado ato é um pensamento valorado, um pensamento com entonação e que adquire, segundo a expressão de Bakhtin, a 'luz do valor'”. 


\section{REFERÊNCIAS}

AMORIM, M. A contribuição de Mikhail Bakhtin: a tripla articulação ética, estética e epistemológica. In: FREITAS, M. T.; SOUZA, S. J.; KRAMER, S. (Orgs.). Ciências Humanas e Pesquisa: leituras de Mikhail Bakhtin, São Paulo: Cortez, 2007. p. 11-25.

ASSMANN, H. Redes digitais e metamorfoses do aprender. Petrópolis: Vozes, 2005.

BAKHTIN, M. Estética da Criação Verbal. São Paulo: Martins Fontes, 2003. . Marxismo e Filosofia da Linguagem. São Paulo: Hucitec,1986.

CHARTIER, A. M. Enseñar a leer y escribir. Una aproximación histórica. México: FCE, 2004.

. Práticas de leitura e escrita - história e atualidade. Belo Horizonte: CEALE/ Autêntica, 2007.

FIORIN, J. L. Introdução ao pensamento de Bakhtin. São Paulo: Ática, 2006.

PORTO, T. M. E. As tecnologias de comunicação e informação na escola; relações possíveis... relações construídas. Revista Brasileira de Educação, v. 11, n. 31, p. 4748, jan./abr. 2006.

ROUANET, S. Fato, ideologia, utopia. Folha de São Paulo, 24 mar. 2002. Caderno MAIS!

SANTOS, L. G. dos et al. Revolução tecnológica, internet e socialismo. São Paulo: Editora Fundação Perseu Abramo, 2003.

SILVA, M.; FONSECA, S. G. Ensinar História no século XXI: em busca do tempo entendido. Campinas: Papirus, 2007.

SMOLKA, Ana Luiza B. Experiência e discurso como lugares de memória: a escola e a produção de lugares comuns. Pro-posições, Campinas, v. 17, n. 2 (50), p. 99-118, maio/ago. 2006.

THOMPSON, E. P. A Miséria da teoria ou um planetário de erros (uma crítica ao pensamento de Althusser). Rio de Janeiro: Zahar Editores, 1981.

. Tradición, revuelta y conciencia de classe. Barcelona: Crítica, 1979. 